\title{
Herbivore induction of the glucosinolate-myrosinase defense system: major trends, biochemical bases and ecological significance
}

\author{
Susanne Textor $\cdot$ Jonathan Gershenzon
}

Received: 16 April 2008/Accepted: 11 October 2008/Published online: 1 November 2008

(C) The Author(s) 2008. This article is published with open access at Springerlink.com

\begin{abstract}
Like many other plant defense compounds, glucosinolates are present constitutively in plant tissues, but are also induced to higher levels by herbivore attack. Of the major glucosinolate types, indolic glucosinolates are most frequently induced regardless of the type of herbivore involved. Over $90 \%$ of previous studies found that herbivore damage to glucosinolate-containing plants led to an increased accumulation of indolic glucosinolates at levels ranging up to 20 -fold. Aliphatic and aromatic glucosinolates are also commonly induced by herbivores, though usually at much lower magnitudes than indolic glucosinolates, and aliphatic and aromatic glucosinolates may even undergo declines following herbivory. The glucosinolate defense system also requires another partner, the enzyme myrosinase, to hydrolyze the parent glucosinolates into biologically active derivatives. Much less is known about myrosinase induction after herbivory compared to glucosinolate induction, and no general trends are evident. However, it is clear that insect feeding stimulates the formation of various myrosinase associated proteins whose function is not yet understood. The biochemical mechanism of glucosinolate induction involves a jasmonate signaling cascade that leads
\end{abstract}

S. Textor · J. Gershenzon $(\varangle)$

Department of Biochemistry, Max Planck Institute

for Chemical Ecology, Hans-Knöll-Strasse 8,

07745 Jena, Germany

e-mail: gershenzon@ice.mpg.de eventually to increases in the transcript levels of glucosinolate biosynthetic genes. Several recently described transcription factors controlling glucosinolate biosynthesis are activated by herbivory or wounding. Herbivore induction of glucosinolates has sometimes been demonstrated to increase protection against subsequent herbivore attack, but more research is needed to evaluate the costs and benefits of this phenomenon.

Keywords Indolic glucosinolates - Jasmonate signaling - Myrosinase associated proteins . Systemic induction · Transcription factors

\section{Introduction}

Among plant anti-herbivore defenses, glucosinolates stand out in several important ways. First, they are low molecular weight amino acid-derived metabolites that have unusually high sulfur content. Their basic skeleton consists of a $\beta$-D-glucose residue linked via a sulfur atom to a ( $Z$ )- $N$-hydroximinosulfate ester and a variable side chain (Halkier and Gershenzon 2006) (Fig. 1). Second, despite the presence of over 120 different glucosinolate structures in plants (Fahey et al. 2001), these substances are confined almost completely to the order Brassicales, which includes the Brassicaceae (cabbage, cauliflower, broccoli and mustard), Capparaceae (capers) and 13 other families. 

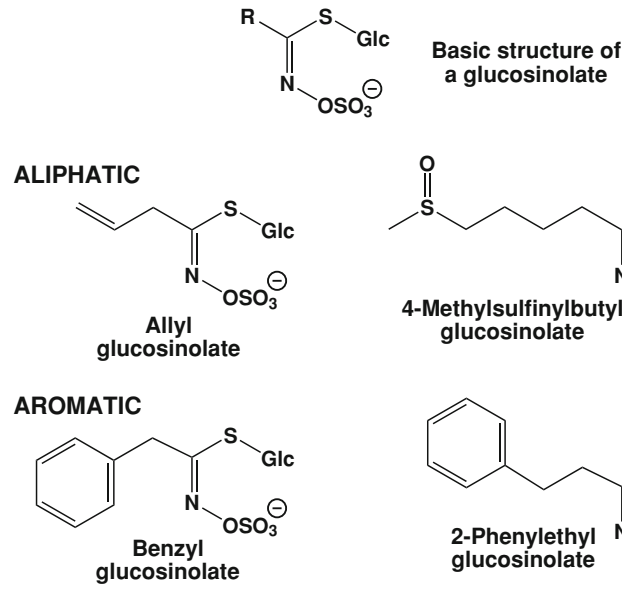

INDOLIC
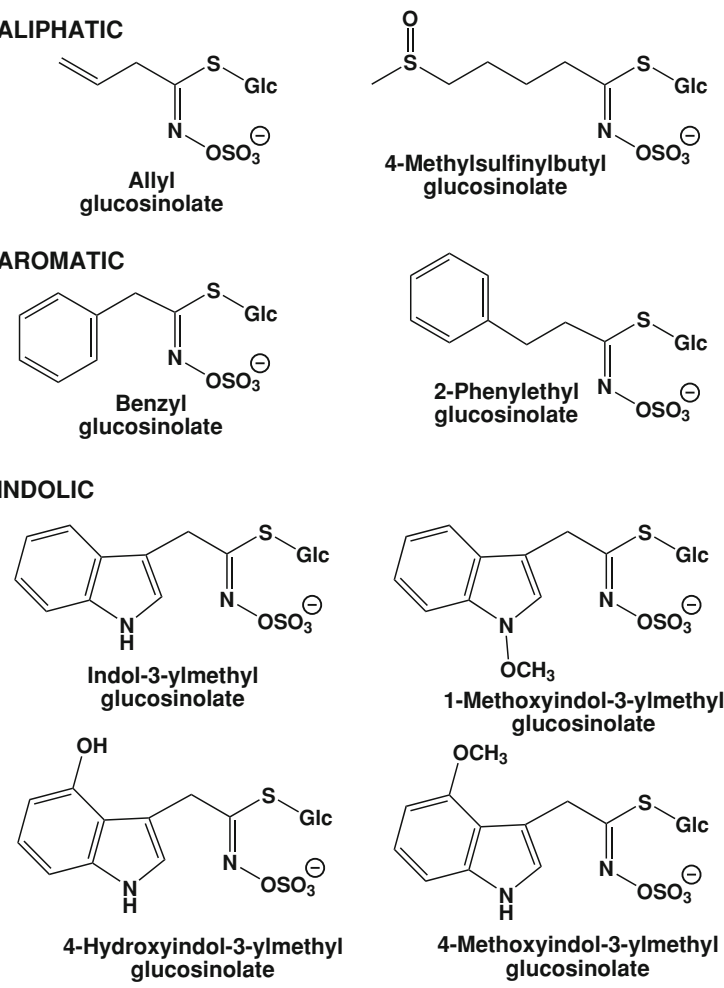

Fig. 1 Basic structure of glucosinolates and examples of the three major types

Third, glucosinolates by themselves have little biological activity, but upon plant damage they are hydrolyzed by thioglucosidase enzymes, known as myrosinases, to form a variety of hydrolysis products, including isothiocyanates, nitriles, epithionitriles and thiocyanates (Bones and Rossiter 1996). These hydrolysis products are responsible for the toxicity and deterrence of glucosinolates to herbivores as well as the taste and smell of cruciferous vegetables, their anti-cancer activity, the role of Brassica crops as biofumigants in agriculture, and nearly all other biological activities of glucosinolates (Halkier and Gershenzon 2006). Glucosinolate hydrolysis is avoided in the plant because glucosinolates and myrosinase are separated in different tissues or cellular compartments. The glucosinolate-myrosinase defense system is distributed throughout the organs of the plant, including leaves, roots, flowers, fruit and seeds.

\section{Glucosinolates and herbivores}

Many of the classic studies on the role of plant metabolites in interactions with herbivores involve glucosinolates (reviewed in Louda and Mole 1991). These compounds have been recognized for years as defenses because of their conversion to noxious products upon plant damage. In general, glucosinolates and their hydrolysis products have negative effects on a wide range of herbivores, including mammals, birds, insects, mollusks, aquatic invertebrates and nematodes (Giamoustaris and Mithen 1995; Halkier and Gershenzon 2006). They exhibit outright toxicity in some cases (Borek et al. 1997; Lazzeri et al. 2004; Li et al. 2000), significant growth inhibitory properties in others (Agrawal and Kurashige 2003; Burow et al. 2006b), and serve as general deterrents to herbivore feeding (Newman et al. 1992; Noret et al. 2005; Siemens and Mitchell-Olds 1996). That the glucosinolate hydrolysis products, rather the parent glucosinolates, are responsible for these effects is clear from studies in which hydrolysis products were tested directly (Agrawal and Kurashige 2003; Borek et al. 1997). In addition, reduction of the rate of hydrolysis by myrosinase inactivation or breeding for low myrosinase levels significantly reduced toxicity and deterrence ( $\mathrm{Li}$ et al. 2000; Newman et al. 1992). When hydrolysis products are explicitly tested, isothiocyanates are often found to be responsible for the activity of the parent glucosinolates (Borek et al. 1997; Burow et al. 2006b; Wittstock et al. 2003). However, many of the hydrolysis products have never been systematically tested against herbivores and some are still being described (Jander, this issue).

Specialist and generalist glucosinolate feeders

Like other classes of anti-herbivore defenses, glucosinolates are not effective against all herbivores. Certain specialists seem to feed without any negative consequences on glucosinolate-containing plants. The same compounds that poison and deter generalist herbivores may function as feeding or oviposition attractants to specialists (Mewis et al. 2002; Miles et al. 2005; Rojas 1999). Attraction from a distance may result from hydrolysis products, while glucosinolates or their hydrolysis products could serve as contact cues (Renwick 2002). 
Specialist insects have developed several strategies to circumvent glucosinolate toxicity by blocking the formation of hydrolysis products. The diamondback moth, Plutella xylostella, has a sulfatase in its gut which cleaves the sulfate residue from the glucosinolate core structure and thus prevents its hydrolysis by myrosinase (Ratzka et al. 2002). This strategy is also evident in a generalist herbivore, the desert locust, Schistocerca gregaria, which possesses an inducible sulfatase activity that is elevated when feeding on plants with high amounts of glucosinolates (Falk and Gershenzon 2007). On the other hand, the cabbage white butterfly, Pieris rapae, directs the myrosinase catalyzed hydrolysis of glucosinolates from isothiocyanates to nitriles with the aid of an endogenous protein called NSP, the nitrile specifier protein (Wittstock et al. 2004). Nitriles appear to be less toxic to herbivorous insects than isothiocyanates (Burow et al. 2006b), and are either excreted with the feces or are further converted to glycine conjugates (Vergara et al. 2006).

Another strategy by which herbivores could avoid glucosinolate toxicity is to rapidly absorb glucosinolates from their digestive tracts before they can be hydrolyzed. In fact, sequestration of dietary glucosinolates is known for several species of insect herbivores, and may have favorable consequences for their own defense (Francis et al. 2001; Müller et al. 2002; Vlieger et al. 2004). Sequestered glucosinolates act as deterrents for predators such as birds, lizards and ants.

\section{Induction of glucosinolates}

In common with many other defense metabolites, glucosinolates are present constitutively in plants, but are also inducible by herbivores. The amounts observed vary depending on the organ, developmental stage, time of day and physical factors of the environment (Bellostas et al. 2007; Brown et al. 2003; Falk et al. 2007; Petersen et al. 2002; Rosa et al. 1994; Shelton 2005), but glucosinolates are usually present throughout the plant at easily detectable levels. Yet following herbivore damage or simulated damage, the amounts of certain glucosinolates are typically induced by several-fold. Glucosinolate induction by herbivory has been documented for a number of plant species. Table 1 provides an overview of published studies of glucosinolate induction giving the effect of herbivory on total glucosinolate content and on the major categories of glucosinolates. The list is organized first by plant species (in alphabetical order), and then by the damaging agent. We have included not only studies employing herbivore damage, but also those using mechanical damage and treatment with plant growth regulators, e.g. jasmonates, to simulate herbivory.

\section{Variation by glucosinolate type}

The three major types of glucosinolates, aliphatic, aromatic and indolic (Fig. 1), are listed separately because they often respond differently to herbivory. This is not unexpected because these types are formed from different amino acid precursors: alanine, isoleucine, leucine, methionine and valine for aliphatic glucosinolates, phenylalanine and tyrosine for aromatic glucosinolates and tryptophan for indolic glucosinolates. In addition, different enzymes are involved, especially at the early stages of biosynthesis (Halkier and Gershenzon 2006) and there are different regulatory factors (Gigolashvili et al. 2007a, b, 2008; Hirai et al. 2007; Sonderby et al. 2007).

Of the three major types of glucosinolates, indolic glucosinolates are most often reported to be induced by herbivory. Considering all of the studies reviewed here, over $90 \%$ describe a significant increase in indolic glucosinolates which ranges from 1.2- to 20 -fold. This generalization holds true regardless of the insect herbivore involved. Representatives of the Coleoptera, Diptera, Homoptera, Hymenoptera and Lepidoptera all induced increased accumulation of indolic glucosinolates. The major indolic glucosinolates present before herbivory in all plants studied is indol-3-ylmethyl glucosinolate (Fig. 1), and typically this compound increases on herbivory. But, in addition, several other indolic glucosinolates present constitutively at low levels, 1-methoxyindol-3-ylmethyl-, 4-methoxyindol-3-ylmethyl- and 4-hydroxyindol3-ylmethyl-glucosinolate (Fig. 1), increase their accumulation many-fold after herbivory or after treatment with jasmonates or salicylic acid (Kim and Jander 2007; Kliebenstein et al. 2002; Mikkelsen et al. 2003; Liang et al. 2006). These findings suggest that such modified indolic glucosinolates have specific roles in anti-herbivore defense (Kim and Jander 2007). 
Significant increases in the other major classes of glucosinolates, aliphatic and aromatic, are also regularly reported after herbivory, though these are typically of much lower magnitude than the increases for indolic glucosinolates (1.2- to 3-fold). Furthermore, aliphatic and aromatic glucosinolates sometimes even decline after herbivory (Birch et al. 1992; Gols et al. 2008; Hopkins et al. 1998; Koritsas et al. 1989, 1991; Müller and Sieling 2006; van Dam and Raaijmakers 2006), a behavior almost never reported for indolic glucosinolates.

Variation by plant species

Among plant species, there are substantial differences in reported glucosinolate inducibility. In part this reflects differences in the type and amount of herbivore damage imposed and the timing and location of the sampling afterwards. However, there are also biological differences in inducibility among species. In fact, within a species even ecotypes (Bidart-Bouzat et al. 2005; Kliebenstein et al. 2002) and cultivars (Birch et al. 1992, 1996) differ in glucosinolate response to herbivory. Interestingly, plants from a wild population of Brassica oleracea were found to have higher glucosinolate concentrations and higher inducibility after herbivory than plants of a B. oleracea cultivar (Gols et al. 2008).

Even greater differences may be revealed by further studies of glucosinolate induction. To date nearly all studies have focused on members of the Brassicaceae, especially Arabidopsis thaliana and Brassica vegetables and oilseed cultivars. Glucosinolate induction has been investigated in only two species from other plant families, Carica papaya (Caricaceae) and Tropaeolum majus (Tropaeolaceae) (Ludwig-Müller et al. 2002). However, these have been analyzed only after application of the growth regulators, jasmonic acid and salicylic acid, and not following actual herbivory. Thus the full range of glucosinolate response to herbivores may still be unknown.

\section{Induction of myrosinase}

Glucosinolates are converted into biologically active hydrolysis products by myrosinase-mediated catalysis. Hence one might predict that an increase in myrosinase activity, like an increase in glucosinolate level, could enhance the defensive potential of glucosinolate-containing plants. This expectation is sometimes met. For example, an approximately 4-fold difference in myrosinase activity among lines of Brassica juncea decreased feeding by Plutella xylostella on the highest activity lines relative to the lowest, but there was no difference in feeding by Spodoptera eridania on these same lines (Li et al. 2000). Similarly, when Brassica rapa populations were artificially selected for divergent myrosinase levels, the high myrosinase population $(\sim 2.5$-fold higher enzyme activity than the low myrosinase population) was more resistant to the flea beetle Phyllotreta cruciferae than the low myrosinase population (Siemens and Mitchell-Olds 1998). In contrast, variation in myrosinase levels had no effect on the feeding behavior of Brevicoryne brassicae on Arabidopsis thaliana (Barth and Jander 2006) or Athalia rosae on Sinapis alba (Müller and Sieling 2006; Travers-Martin and Müller 2007).

Thus changes in myrosinase activity could impact a plant's ability to defend itself against herbivores. But, unfortunately myrosinase activity has not been measured nearly as frequently as glucosinolate content, and the reports available show no clear trend. Myrosinase activity increases up to 3-fold after specialist herbivore attack by $P$. xylostella on B. rapa (Siemens and Mitchell-Olds 1998) and by A. rosae on S. alba (Martin and Müller 2007; Travers-Martin and Müller 2007). However, feeding by the generalist lepidopteran, Spodoptera frugiperda on $S$. alba had no influence on myrosinase activity (Travers-Martin and Müller 2007). Curiously in $S$. alba there were substantial changes in the relative amount of myrosinase in soluble versus insoluble fractions, as measured under non-denaturing conditions. Insoluble activity typically increased up to 3-fold, with only low or no increase in soluble activity (Travers-Martin and Müller 2007). Insolubility does not appear to compromise catalytic ability, and has been attributed to complexation with associated proteins (Eriksson et al. 2002). Some studies on myrosinase activity in response to herbivores even report a net decline in activity, such as after $A$. rosae feeding on B. juncea (Müller and Sieling 2006) and P. xylostella feeding on Brassica napus (Pontoppidan et al. 2005). These declines were due to decreases in soluble activity, while insoluble activity was not 
affected. In A. thaliana, a decline in myrosinase activity was observed in hypocotyls after methyl jasmonate application (Alvarez et al. 2008).

Myrosinase levels have also been followed by transcript level measurements. Significant declines were apparent in gene transcripts encoding the A. thaliana myrosinases tggl and tgg2 in most ecotypes after infestation with the specialist aphid, $B$. brassicae or the generalist aphid, Myzus persicae (Kusnierczyk et al. 2007). A similar trend was seen earlier for myrosinase transcripts in B. napus infested with B. brassicae (Pontoppidan et al. 2003), but myrosinase transcript levels rose 1.5 -fold in $B$. napus after $P$. xylostella feeding (Pontoppidan et al. 2005) and increased after jasmonate treatment in A. thaliana (Jost et al. 2005). Unfortunately, the effects of these transcript changes on myrosinase activity have not been documented. Moreover, the effects of changes in myrosinase activity on plant resistance are not well understood. Further experiments are needed to investigate the effect of herbivory on myrosinase levels. These results along with studies of transgenic plant lines containing varying concentrations of both glucosinolates and myrosinases would be helpful in assessing how myrosinase levels affect the defensive potential of glucosinolates.

Proteins associated with myrosinase

The outcome of glucosinolate hydrolysis in plants is mediated not only by myrosinase, but by other plantderived proteins including ESP (Burow et al. 2006a; Lambrix et al. 2001), ESM1 (Zhang et al. 2006) and TSP (Burow et al. 2007) that alter the composition of hydrolysis products. Transcript levels of both ESP and ESM1 in A. thaliana were reported to decline after feeding by the aphids $M$. persicae and $B$. brassicae (Kusnierczyk et al. 2007).

Other types of proteins are closely associated with myrosinase and have been designated as myrosinase binding proteins, myrosinase associated proteins and myrosinase binding protein-related proteins (Rask et al. 2000). First noted by their co-precipitation with myrosinase in the presence of antibodies raised against myrosinase, these proteins appear to bind myrosinase in insoluble complexes (Eriksson et al. 2002), although this behavior may simply be an artifact of extraction. Transcripts of myrosinase associated proteins and myrosinase binding proteins have been shown to be induced locally and systemically in a variety of plant systems by both specialist and generalist herbivores (Andreasson et al. 1999; Kusnierczyk et al. 2007; Pontoppidan et al. 2003, 2005; Reymond et al. 2004; Sarosh and Meijer 2007) as well as by mechanical wounding and jasmonate treatment (Andreasson et al. 1999; Sarosh and Meijer 2007; Sasaki-Sekimoto et al. 2005: Taipalensuu et al. 1996, 1997), implying that there may be a role for these proteins in plant protection. They have been proposed to stabilize myrosinase activity or alter other enzymatic properties, such as substrate or product specificity, but no supporting evidence is yet available (Eriksson et al. 2002; Rask et al. 2000).

In summary, there is no general induction of myrosinase activity after herbivory. Instead, insect feeding triggers appearance of various associated proteins whose functions remain to be elucidated.

\section{Biochemical bases of induction}

Our knowledge of how plants respond to herbivory at the biochemical and molecular levels has expanded dramatically in recent years. Since a major portion of this research has been carried out with Arabidopsis thaliana, which happens to contain glucosinolates and myrosinases, much has been learned that is relevant to their induction, especially in the area of signaling.

Jasmonate signaling

One of the major findings is that the induction of glucosinolates is mediated by jasmonate signaling. As already seen in Table 1, jasmonate or methyl jasmonate treatments, like herbivory, stimulated an induction in glucosinolate content in every species tested. As with herbivory, indolic glucosinolates were most frequently induced, but aliphatic and aromatic glucosinolates were also induced in a number of species. At the molecular level, experiments with A. thaliana showed that jasmonates increase the transcript levels of various glucosinolate biosynthetic genes, including those for all of the known steps of the core pathway of indolic glucosinolates (Fig. 2) (Halkier and Gershenzon 2006). Included on this list are (1) CYP79B2 and CYP79B3: catalyzing the oxidation of tryptophan to indol-3-acetaldoxime (Brader et al. 


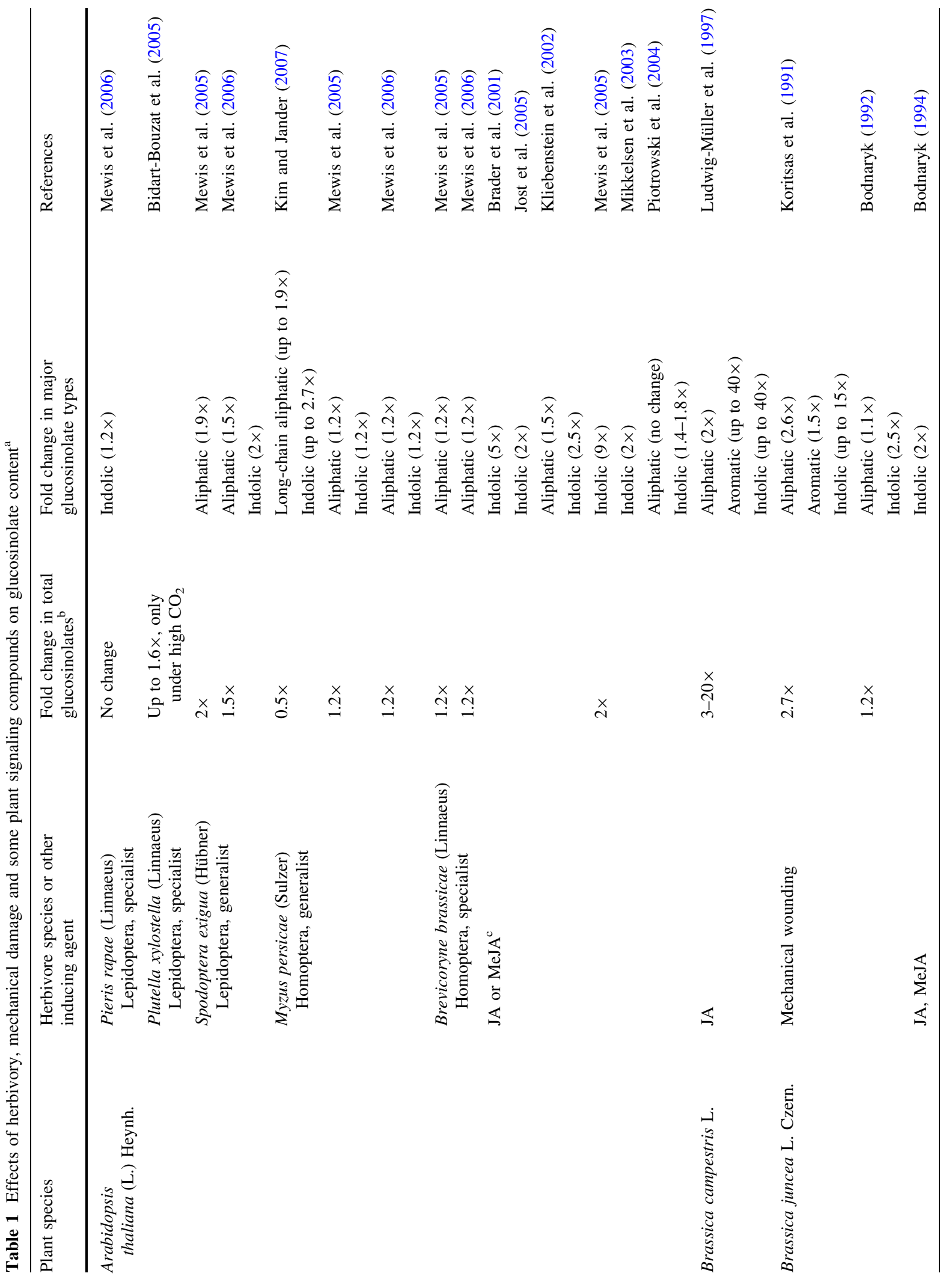




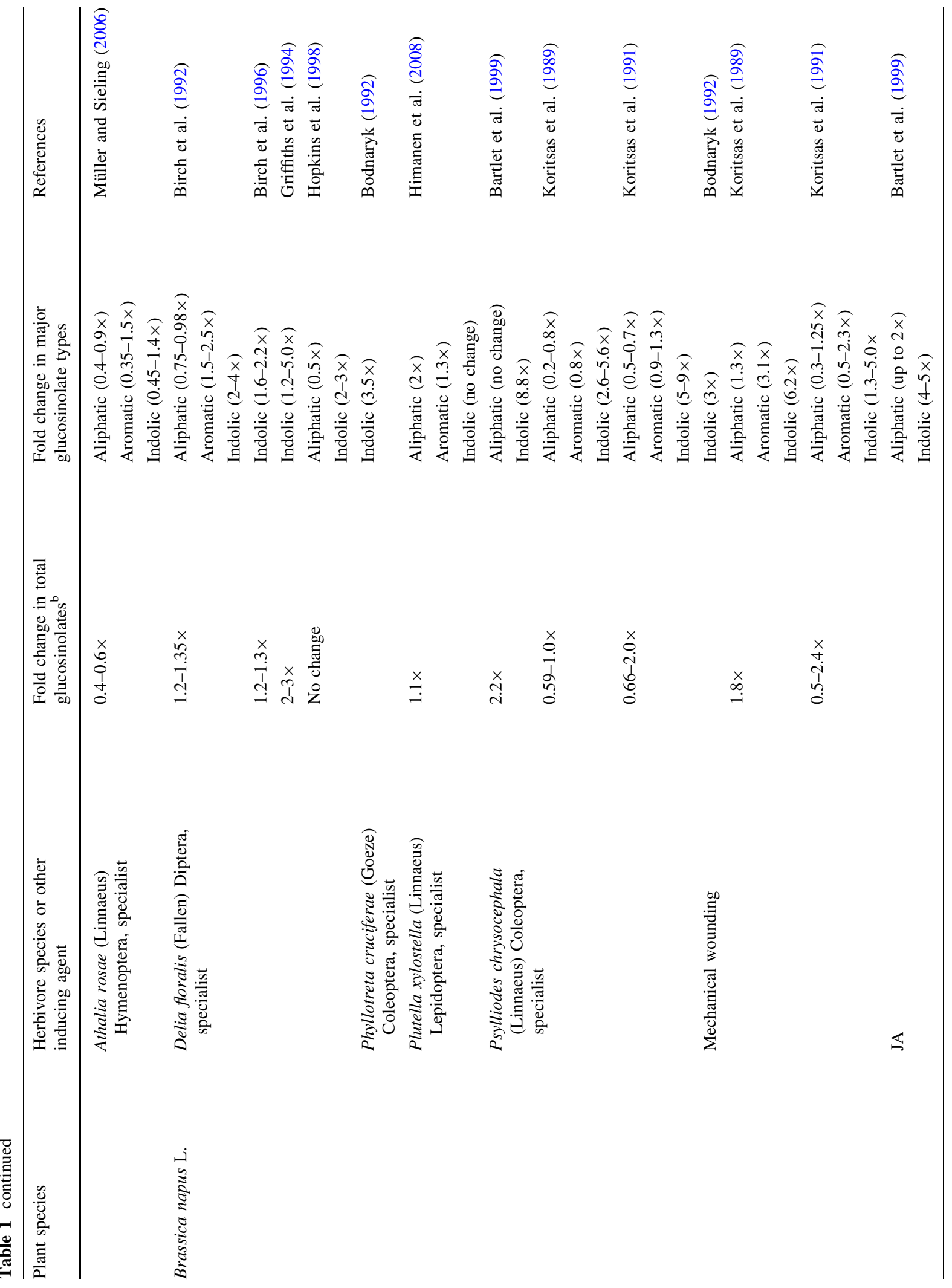




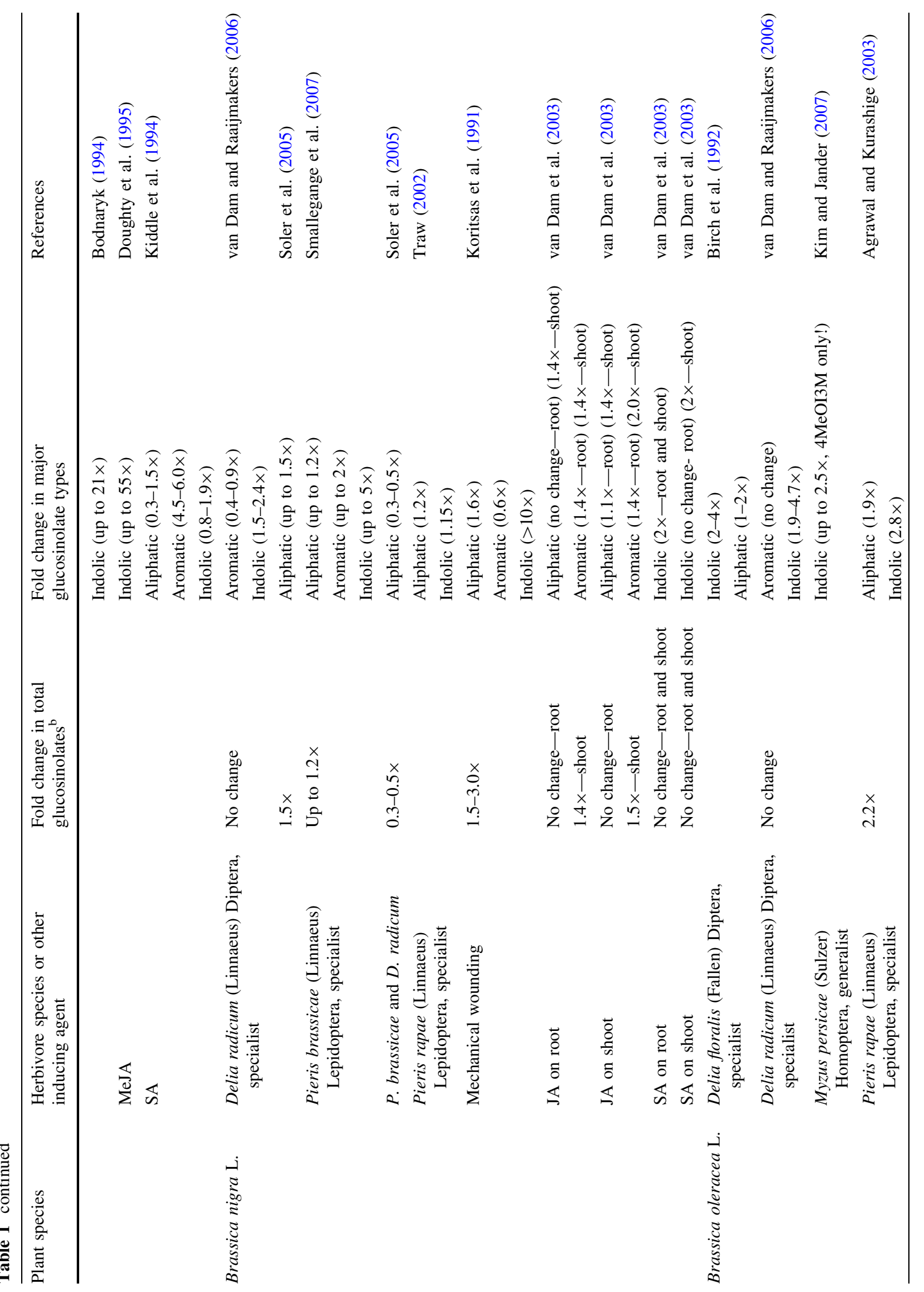




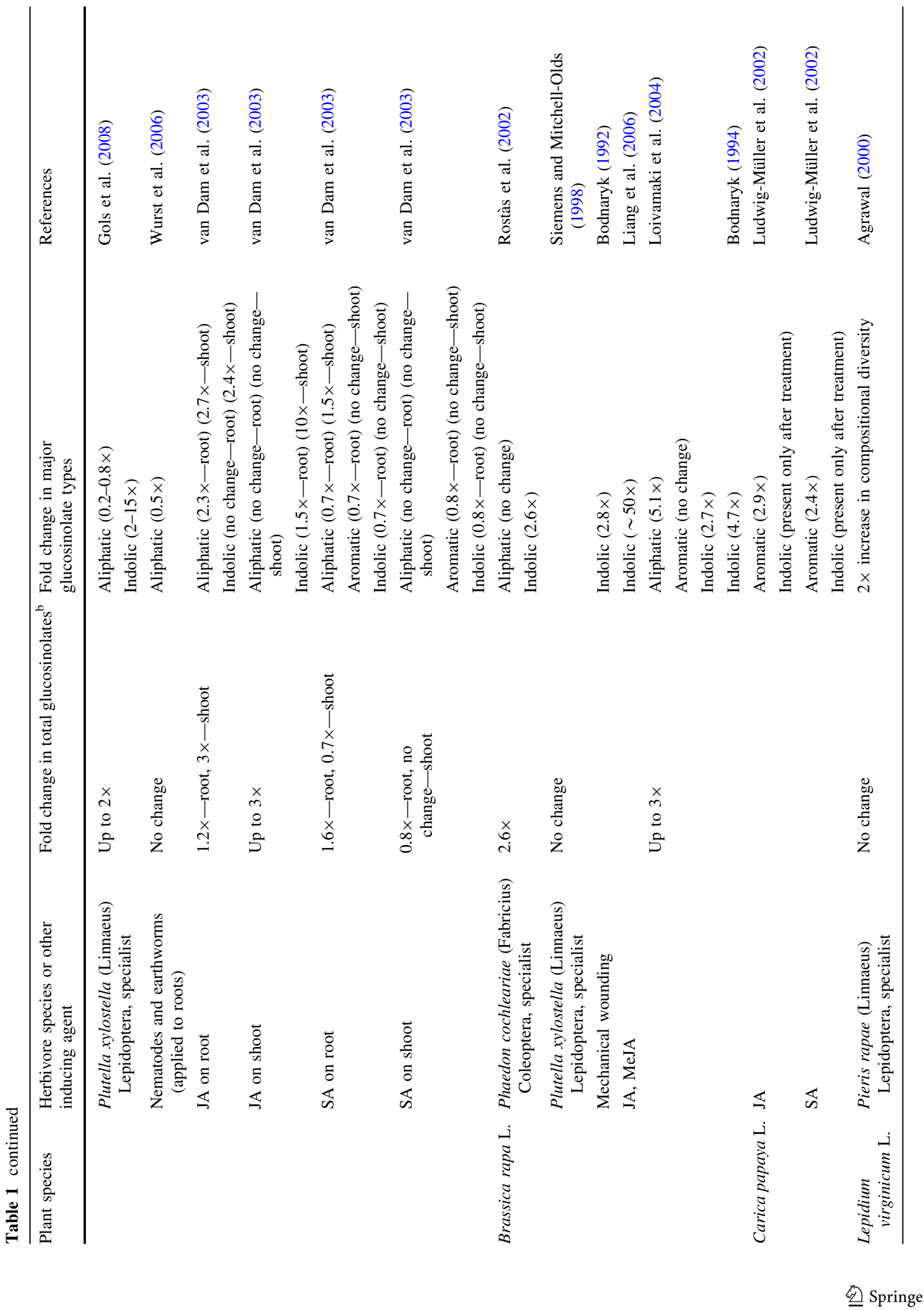




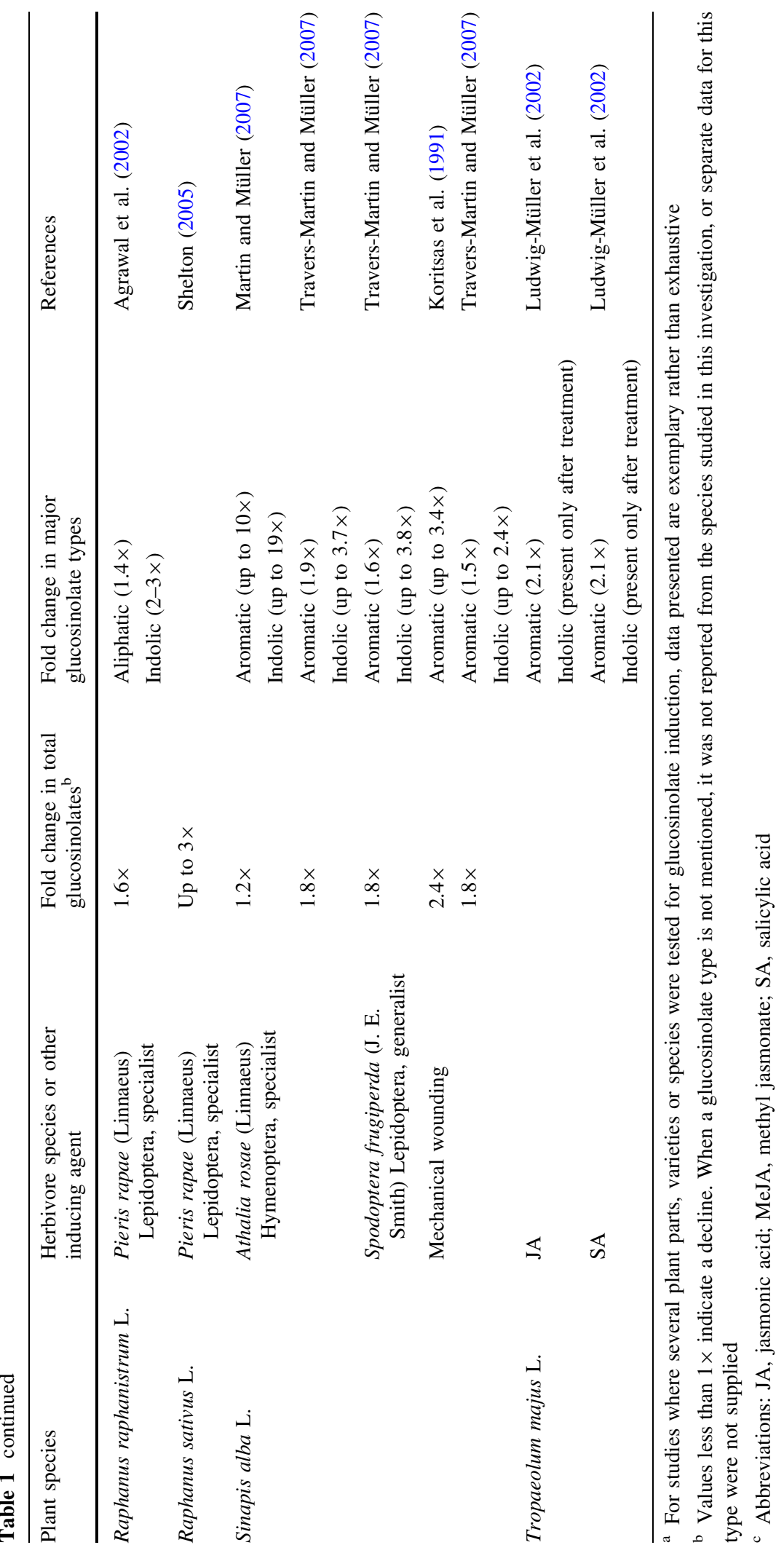


a

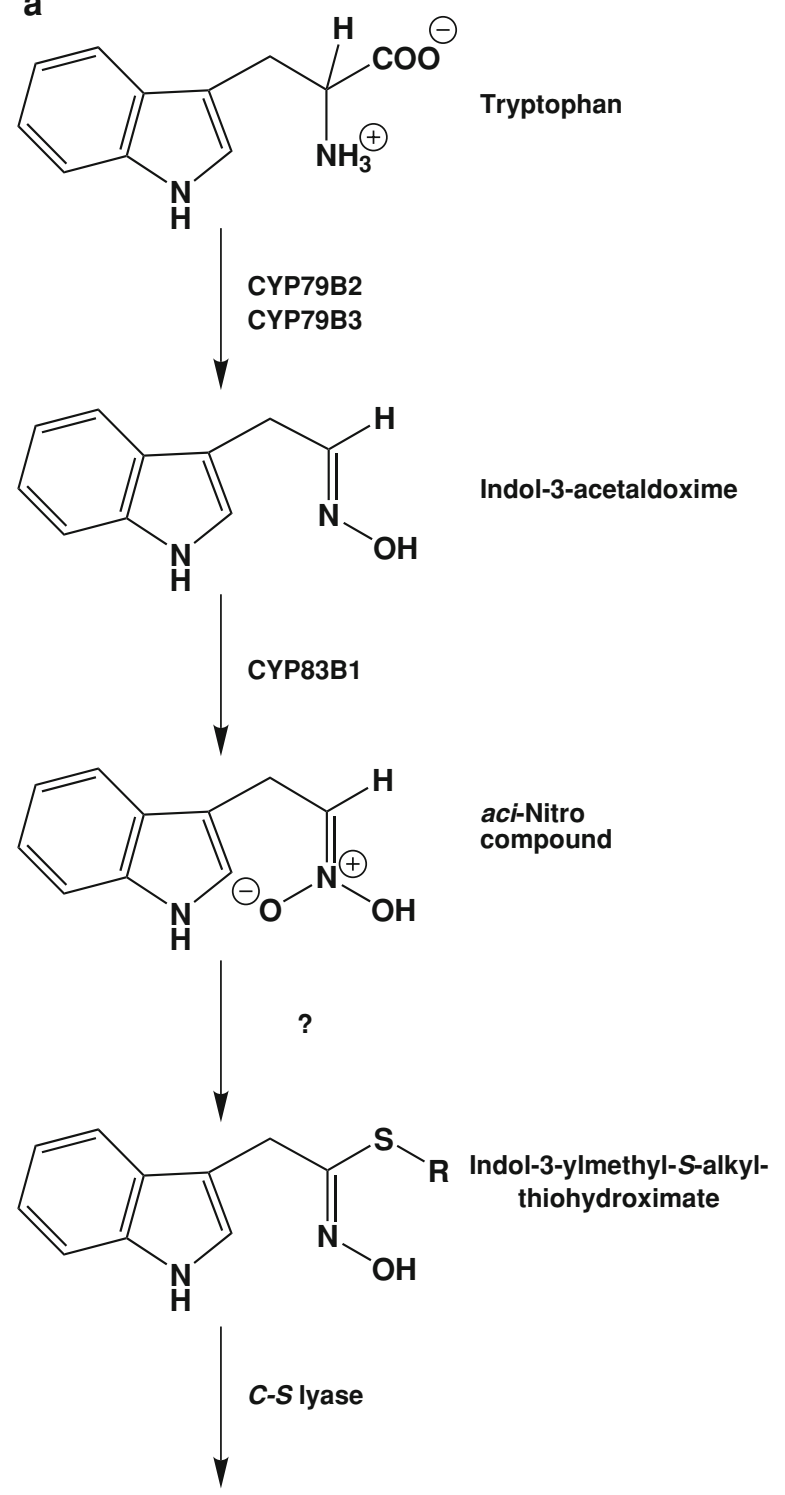

Fig. 2 Outline of the core pathway of indolic glucosinolate biosynthesis listing the enzymes catalyzing each step. The identity of the CYP83B1 product and the nature of the following step are still unknown. Aliphatic and aromatic glucosinolate biosynthesis are similar but the aliphatic pathway begins with alanine, methionine or a branched chain amino b<smiles>O/N=C(/S)Cc1c[nH]c2ccccc12</smiles><smiles>O/N=C(/Cc1c[nH]c2ccccc12)SCl</smiles>
(Sulfotransferase)

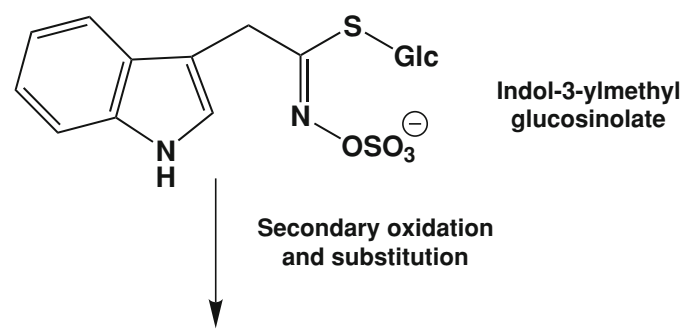
Indol-3-ylmethy glucosinolate acid instead of tryptophan, while the aromatic pathway begins with phenylalanine or tyrosine. In the case of methionine, and some other amino acids, the basic amino acid structure is often subject to side chain elongation before entering the core pathway

ylmethyl desulfoglucosinolate (Brader et al. 2001; Sasaki-Sekimoto et al. 2005) and (5) AtST5a: a sulfotransferase that forms the final indol-3-ylmethyl glucosinolate (Piotrowski et al. 2004). Interestingly, transcripts encoding various steps of tryptophan biosynthesis are also elevated (Brader et al. 2001; SasakiSekimoto et al. 2005). 
Further confirmation of the role of jasmonate signaling in glucosinolate induction comes from studies with coil, an A. thaliana mutant line blocked in jasmonate signaling. The coil mutant had lower levels of constitutive glucosinolates than the corresponding Columbia-0 wild-type, and displayed virtually no induction of indolic glucosinolates in response to various herbivores (Brader et al. 2001; Mewis et al. 2005, 2006; Mikkelsen et al. 2003). In addition, most of the glucosinolate biosynthetic gene transcripts elevated by herbivory on wild-type plants responded oppositely or not at all in coil (Mewis et al. 2006).

\section{Other signaling pathways}

Since coil plants still showed induction of aliphatic glucosinolates after herbivory (Mewis et al. 2005, 2006), signaling cascades besides that of jasmonate must be involved in regulating glucosinolate accumulation. Ethylene signaling is implicated since the ethylene-insensitive mutant etrl did not show any induction of aliphatic glucosinolates in response to the herbivores, Myzus persicae, Brevicoryne brassicae and Spodoptera exigua, as the wild-type did (Mewis et al. 2005, 2006). At the same time, there was no elevation of the transcript levels of aliphatic glucosinolate biosynthetic genes in herbivore-damaged etrl plants, as was observed in the wild-type (Mewis et al. 2006). Experiments with another ethylene signaling mutant, $c t r l$, showed little difference in glucosinolate profile from that of the wildtype (Mikkelsen et al. 2003).

Salicylate-dependent signaling is known to be involved in plant defense responses to aphids and other herbivores. Accordingly, salicylic acid (SA) application led to the induction of various glucosinolate types in different species (Kiddle et al. 1994; Ludwig-Müller et al. 2002, van Dam et al. 2003), but also caused some declines in glucosinolate content (Kiddle et al. 1994; van Dam et al. 2003). Experiments with SA-signaling mutants of $A$. thaliana supported both of these trends. The induction of aliphatic glucosinolates by aphids and $S$. exigua in wild-type A. thaliana was not observed in the $n p r 1$ mutant (Mewis et al. 2006), suggesting SA involvement in promoting induction. However, in SAoverproducing mutants the jasmonate induction of indolic glucosinolates was inhibited (Mikkelsen et al.
2003), consistent with other reports of SA antagonism of jasmonate signaling. In A. thaliana, salicylic acid application specifically promoted accumulation of one species of indolic glucosinolate, 4-methoxyindol3-ylmethyl glucosinolate (Fig. 1) (Kliebenstein et al. 2002; Mikkelsen et al. 2003), but SA did not seem to be involved in the induction of this compound in A. thaliana by M. persicae (Kim and Jander 2007).

Transcription of biosynthetic genes

Regardless of the signaling cascades involved herbivory leads to the up-regulation of glucosinolate biosynthetic gene transcripts by herbivores. A wide range of $A$. thaliana genes is activated by herbivory, including those encoding the CYP79 and CYP83 oxidation steps of the core pathway of aliphatic and indolic glucosinolates (Fig. 2) (Kusnierczyk et al. 2007; Mewis et al. 2006; Reymond et al. 2004), as well as the glucosyltransferase step of the core pathway (Mewis et al. 2006). Herbivory and mechanical wounding also increase the expression of genes involved in forming the elongated side chains of aliphatic glucosinolates, including genes encoding the methionine aminotransferases (BCAT3 and BCAT4, Knill et al. 2008; Schuster et al. 2006), the methylthioalkylmalate synthases (MAM1 and MAM3, Mewis et al. 2006) and enzymes of the pathway to tryptophan, the substrate for indolic glucosinolates (Kusnierczyk et al. 2007; Reymond et al. 2004). These results underscore the fact that induced glucosinolate accumulation in plants is likely to result from de novo synthesis rather than transport from other organs, and that biosynthesis is controlled at the level of transcription of pathway genes.

Curiously, the increase in biosynthetic gene transcripts is not always accompanied by increased glucosinolate accumulation. For example, Pieris rapae induced the expression of several genes of aliphatic glucosinolate biosynthesis when feeding on A. thaliana, but there was no observable change in aliphatic glucosinolate content up to 3 days after feeding (Mewis et al. 2006). In contrast, both glucosinolate biosynthetic gene transcripts and glucosinolate accumulation were induced by 3 days of Spodoptera exigua feeding in the same study. Thus, there must be factors other than biosynthetic gene expression and signal transduction pathways that regulate glucosinolate induction. Other control points 
could include precursor supply, post-transcriptional regulation of biosynthetic enzymes, expression of regulatory genes and cellular compartmentation.

\section{Regulatory genes}

There has been some exciting recent progress in the identification of regulatory genes that control glucosinolate biosynthesis. Using knock-out and overexpressing lines of $A$. thaliana, a number of regulatory genes have been discovered that significantly modulate glucosinolate levels. Several of these affect both aliphatic and indolic glucosinolate formation including IQDI, a calmodulin-binding protein (Levy et al. 2005), AtDof1.1, a DNA binding-with-one-finger transcription factor (Skirycz et al. 2006) and TFL2, a heterochromatic protein (Bennett et al. 2005; Kim et al. 2004). While expression of these three genes promotes glucosinolate formation, a fourth regulatory gene, an EIL family transcription factor named SLIMI expressed under sulfur-limiting conditions, inhibits glucosinolate formation (Maruyama-Nakashita et al. 2006). Other newly-discovered glucosinolate transcription factors are members of the R2R3 MYB gene family. Some of these affect indolic glucosinolate formation specifically, including MYB34 (ATR1) (Celenza et al. 2005), MYB51 (Gigolashvili et al. 2007a) and MYB122 (Gigolashvili et al. 2007a), by activating genes of the indolic glucosinolate pathway as well as genes of tryptophan biosynthesis. Other MYB proteins, namely MYB28, MYB29 and MYB76, control aliphatic glucosinolate biosynthesis by activating genes of the core aliphatic pathway, methionine side chain elongation and some reactions of general sulfur metabolism (Gigolashvili et al. 2007b, 2008; Hirai et al. 2007; Sonderby et al. 2007).

Many of these regulatory genes appear to play a role in glucosinolate induction since their expression is triggered by touch, mechanical wounding, methyl jasmonate treatment or insect infestation (Table 2). For example, the activation of indolic glucosinolate biosynthesis by herbivory may be especially triggered by MYB51 since, of the indolic glucosinolate transcription factors described, its transcript level increased fastest, within $10 \mathrm{~min}$ of wounding, whereas MYB122 responded only after a delay of $1 \mathrm{~h}$ and MYB34 did not react to wounding at all (Gigolashvili et al. 2007a). Among the aliphatic glucosinolate transcription factors described, expression of MYB28, MYB29 and MYB76 were induced 1 min after mechanical wounding (Gigolashvili et al. 2008). In contrast, transcript of MYB29 was induced by methyl jasmonate and repressed by SA, but MYB28 and MYB76 did not respond to these compounds (Gigolashvili et al. 2008). Instead, MYB28 transcript level was enhanced by glucose (Gigolashvili et al. 2007b). This response may indicate that aliphatic glucosinolate biosynthesis is also controlled by the availability of carbohydrate and that synthesis may not occur unless an adequate supply of carbohydrate is present. Alternately, glucose-enhanced transcription of MYB28 may provide a convenient mechanism for herbivore damage to trigger glucosinolate induction, since tissue disruption will result in local increases in glucose as a product of myrosinase-catalyzed glucosinolate hydrolysis. Glucose is known to function as a signal in many plant processes (Price et al. 2004). Thus, MYB51 (indolic glucosinolates) and any of the aliphatic glucosinolate MYB transcription factors known could be important components of the signaling chain causing glucosinolate induction after herbivory.

Biochemical basis of myrosinase induction

Compared to glucosinolates, much less is known about the biochemical basis of myrosinase induction. The numerous reports of changes in myrosinase transcript level following herbivory (Jost et al. 2005; Kusnierczyk et al. 2007; Pontoppidan et al. 2003, 2005) suggest that activity is regulated by gene expression. However, myrosinase activity could also be modulated by post-translational glycosylation, complexation with associated proteins (Burow et al. 2006a; Eriksson et al. 2002; Zhang et al. 2006) or levels of the essential cofactor ascorbate (Burmeister et al. 2000). Changes in the abundance of different myrosinase species with varying substrate specificities could in theory also alter the defensive potential of the glucosinolate-myrosinase system, but there is no evidence as yet supporting this possibility.

\section{Ecological significance of glucosinolate induction}

Although the induction of glucosinolates, especially indolic glucosinolates, by herbivore damage is a general response of most glucosinolate-containing 


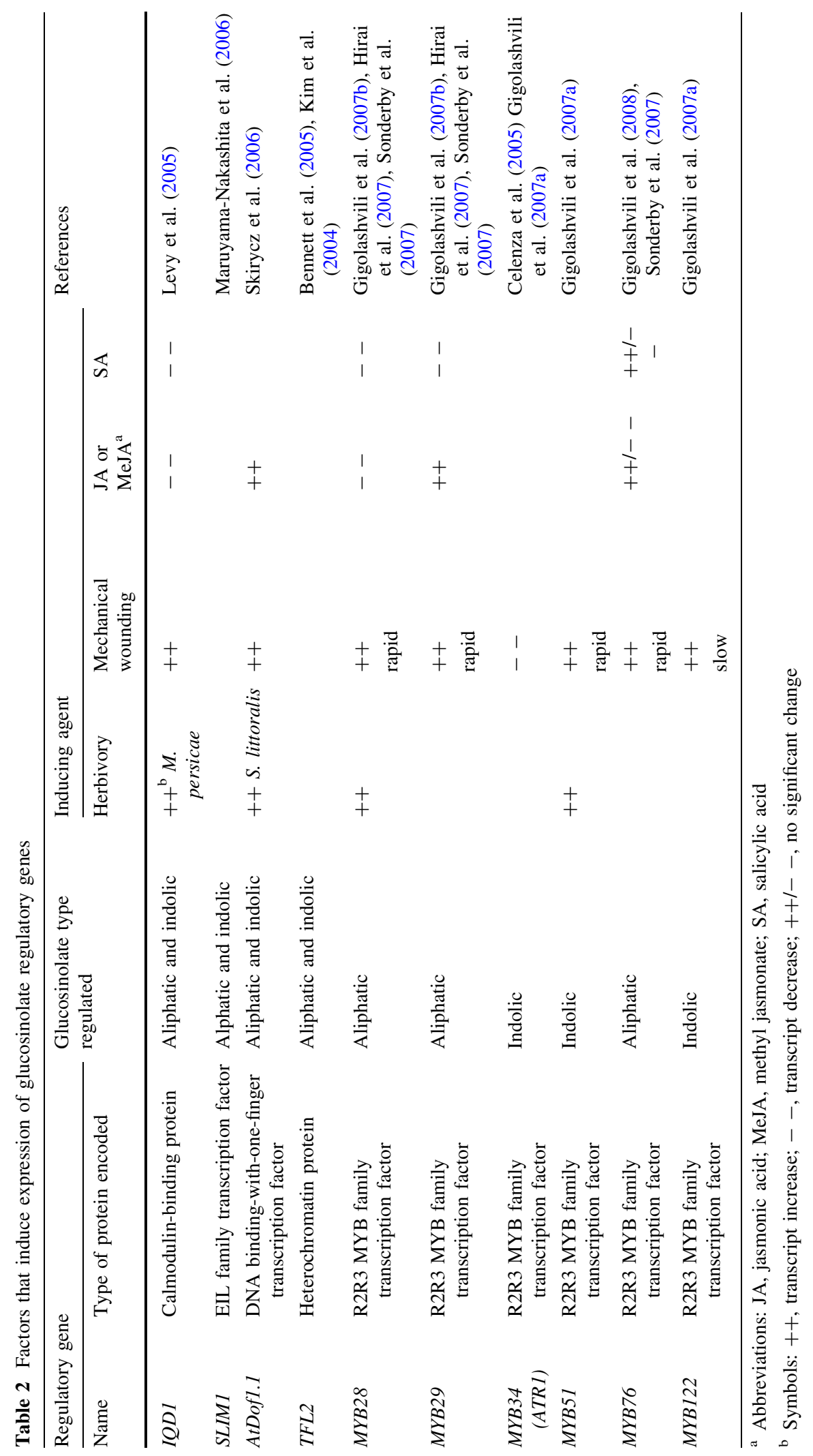


plants studied, the ecological consequences of this phenomenon are not always clear. To evaluate the significance of glucosinolate induction, we here summarize the pattern of response to different types of herbivores and other enemies, the timing and location of the response and whether or not there are any actual benefits in plant protection.

\section{Variation with herbivore guild}

A striking trend visible in Table 1 is that herbivores from different guilds have very distinct effects on glucosinolate profiles. Aphids, which are sucking insects, trigger less induction than chewing insects, including beetles, caterpillars and flies, and may even cause a decline in total glucosinolates. Aphids feed only on single cells of the phloem and so may not trigger the myrosinase-catalyzed breakdown of glucosinolates to active hydrolysis products since glucosinolates and myrosinases are thought to be located in separate cells (Barth and Jander 2006). Thus, from the plant's perspective, induction of glucosinolates may not have any defensive value against aphids. However, recent investigations on Myzus persicae feeding on Arabidopsis thaliana demonstrated that one indolic glucosinolate species, 4-methoxyindol-3-ylmethyl glucosinolate (Fig. 1), was induced on aphid infestation. Indolic glucosinolates are known to be chemically less stable than aliphatic glucosinolates and so may be effective defenses even without myrosinase due to non-enzymatic conversion to toxic products (Jander, this issue). In support of this proposition, indolic glucosinolates were found to be mostly degraded after passage through $M$. persicae while aliphatic glucosinolates were not (Kim and Jander 2007). Glucosinolate hydrolysis within an insect such as $M$. persicae may be due to the action of glucohydrolases produced by the insect or bacterial symbionts, as well as to non-enzymatic processes. Consistent with their defensive role, indolic glucosinolates, especially 4-methoxyindol-3-ylmethyl and 1-methoxyindol-3-ylmethyl glucosinolates (Fig. 1), significantly reduce aphid reproduction (Kim and Jander 2007).

Although there is much less information on myrosinase induction by herbivores compared to glucosinolate induction, a similar trend is evident with regard to variation among guilds. Aphid infestation always leads to a decline in myrosinase transcript level (Kusnierczyk et al. 2007; Pontoppidan et al. 2003). Attack by chewing insects, on the other hand, did not cause a decline in myrosinase in the majority of cases, but rather triggered an increase in myrosinase enzyme activity or transcript level (Martin and Müller 2007; Pontoppidan et al. 2005; Siemens and Mitchell-Olds 1998; Travers-Martin and Müller 2007) or had no effect (Travers-Martin and Müller 2007).

Variation between generalists and specialists

In comparing the results of experiments with generalist and specialist herbivores, no dramatic differences in glucosinolate induction patterns can be discerned. This trend is consistent with the fact that generalist and specialist herbivores have remarkably similar effects on gene expression profiles, at least in A. thaliana (Kusnierczyk et al. 2007; Moran et al. 2002; Reymond et al. 2004). However, there is a tendency for plants to decrease their levels of aliphatic and aromatic glucosinolates more often in response to specialist than generalist herbivores. For example, feeding of Delia floralis and D. radicum led to declines of aliphatic or aromatic glucosinolates of up to $60 \%$, while indolic glucosinolates increased (Birch et al. 1992; Hopkins et al. 1998; van Dam and Raaijmakers 2006). Attack of two specialist herbivores, one above ground and one below ground led to a $50-70 \%$ reduction in leaf glucosinolate content (Soler et al. 2005). If a plant detects attack by a specialist rather than a generalist, it may be a sensible strategy to avoid committing further resources to glucosinolate production. Certain specialist herbivores are known to have biochemical mechanisms allowing them to circumvent the effects of glucosinolates (Ratzka et al. 2002; Wittstock et al. 2004). Studies on myrosinase induction by herbivores are few in number, but these also show no dramatic differences in the effects of generalist versus specialist feeders.

Induction by mechanical wounding and pathogens

Simulation of herbivory by mechanical wounding also triggers increases in plant glucosinolate content (Griffiths et al. 1994; Koritsas et al. 1989). However, the magnitude of this increase is rarely equivalent to 
that caused by actual herbivory, perhaps because mechanical damage treatments are usually administered only once while actual herbivore damage involves repeated wounding over a long period of time (Mithöfer et al. 2005). When mechanical wounding of Brassica napus cotyledons was divided among two consecutive days, rather than being given on a single day, there was greater glucosinolate induction (Bodnaryk 1992).

Herbivores are not the only plant enemies that can induce glucosinolate formation. Increases in plant glucosinolate content, especially in indolic glucosinolates, are also frequently reported in response to the attack of fungi and bacteria (Brader et al. 2001; Ludwig-Müller et al. 1997, 2002; Rostàs et al. 2002; Vierheilig et al. 2000). These increases are not surprising in light of the fact that glucosinolates are also considered as defenses against some microorganisms, especially nectrotrophs ( $\mathrm{Li}$ et al. 1999; Mari et al. 2002; Smith and Kirkegaard 2002). However, the magnitude of the increase is sometimes less than that induced by herbivores or not evident at all (Doughty et al. 1995; Kliebenstein et al. 2005; Koritsas et al. 1989).

If the increase in glucosinolates in response to herbivory protects plants against further attack, more extensive herbivory should result in greater glucosinolate induction. This trend holds for damage caused by the lepidopteran Pieris rapae (Shelton 2005), the dipterans D. floralis (Hopkins et al. 1998) and $D$. radicum (Soler et al. 2005), and mechanical damage meant to simulate herbivory (Bodnaryk 1992), but the effect is not always linear.

Local versus systemic induction

The presence of herbivores on one part of the plant is often a reliable indication that other parts of the plant will be attacked as well in due course. Hence it is not surprising that herbivory causes not only local induction of glucosinolates, but also induction in more distant parts of the plant. Several examples of this phenomenon have been noted in the studies under review here. For example, when the flea beetle Psylliodes chrysocephala was bagged on the third true leaf of B. napus, indolic glucosinolates increased over 7-fold in the seventh as well as the third leaf (Bartlet et al. 1999). P. chrysocephala also increases indolic glucosinolates substantially in undamaged plant parts adjacent to the attack site (Koritsas et al. 1991). However, sometimes changes in adjacent parts are much lower in magnitude or not significant at all (Kim and Jander 2007; Martin and Müller, 2007; Travers-Martin and Müller 2007; van Dam and Raaijmakers 2006). For example, feeding by the specialist hymenopteran Athalia rosae caused a more than 9-fold increase in benzyl glucosinolate levels in damaged leaves of Sinapis alba, but only slightly more than a 2-fold increase in undamaged, flanking leaves (Martin and Müller 2007). Induction of indol3-ylmethyl glucosinolate in this study was over 19-fold in damaged leaves, but was not seen in undamaged leaves.

Long distance shoot-to-root transfer of the induction signal also occurs. Root herbivory by $D$. floralis on Brassica, sp., which increased indolic glucosinolates in the roots, also caused lesser increases in the leaves (Griffiths et al. 1994). In the other direction, above ground herbivory by $P$. chrysocephala increased glucosinolates in the roots of Brassica, spp. (Koritsas et al. 1991). These long distance inductions are probably mediated by signaling agents, such as jasmonic acid and salicylic acid, since treatment of either the shoot or root with these compounds sometimes leads to glucosinolate induction in the other half of the plant (Ludwig-Müller et al. 1997; van Dam et al. 2003). For a more detailed comparison of glucosinolate induction in shoots and roots, see van Dam et al. (this issue).

\section{Relaxation time}

If glucosinolate induction is a response to a specific threat, it might be predicted that the level of these defense compounds would return to normal, uninduced levels after a certain period of time. Indeed this is what has been observed in at least one report. The large increase in indolic (up to 19-fold) and aromatic (up to 9-fold) glucosinolates seen in $S$. alba in response to $24 \mathrm{~h}$ of $A$. rosae feeding reached a peak 1 day after the start of feeding and was almost completely abolished by 3 days after feeding (Martin and Müller 2007). Unfortunately, nearly all other studies reviewed here measured glucosinolate content at only one time point following herbivory. However, a similar relaxation of glucosinolate induction was noted in A. thaliana ecotype Ler after jasmonic acid treatment (Kliebenstein et al. 2002). Aliphatic 
glucosinolate induction of 15-fold was observed $24 \mathrm{~h}$ after treatment, but this was no longer evident by $48 \mathrm{~h}$. Indolic glucosinolates, though, remained at their induced level (approximately 2-fold that of control plants) at $48 \mathrm{~h}$.

Benefits of induction

The ecological significance of glucosinolate induction would be most convincingly demonstrated if the change in glucosinolate content observed actually increased plant protection against herbivory. In fact, glucosinolate induction has been shown to be associated with the reduced performance of herbivores in several experimental systems including $P$. rapae on Arabidopsis lyrata and Brassica oleracea (Agrawal and Kurashige 2003), Pieris brassicae on Brassica nigra after root damage by $D$. radicum (Soler et al. 2005), Spodoptera exigua and Heliothis zea on Lepidium virginicum (Agrawal 2000) and S. exigua, Myzus persicae and Brevicoryne brassicae on A. thaliana (Mewis et al. 2005). However, glucosinolate induction was not correlated with larval performance, feeding behavior or plant damage in other systems, including Phyllotreta cruciferae on Brassica, sp. (Bodnaryk 1992; Bodnaryk and Palaniswamy 1990), P. rapae on L. virginicum (Agrawal 2000) and A. rosae on S. alba (TraversMartin and Müller 2007). In these studies, increases in glucosinolate content are reported to negatively affect both specialist and generalist feeding insects, but all of the insect herbivores that were unaffected by an increase in glucosinolate content are specialist feeders. Since two specialist lepidopterans, Plutella xylostella (Ratzka et al. 2002) and P. rapae (Wittstock et al. 2004) are known to have specific mechanisms of circumventing the toxicity of glucosinolates, an increase in glucosinolate content may be less likely to be an effective defense against this type of herbivore. But, plants could induce their glucosinolate content anyway if they are not able to distinguish the type of herbivore attacking them. To be effective as an induced defense, it may not be necessary to increase the overall glucosinolate content, but only to change its distribution. Damage to Raphanus sativus by $P$. rapae was shown to increase the small-scale spatial variation of glucosinolates within leaves. This may reduce herbivory by preventing herbivores from readily identifying less defended areas of the leaf or synchronizing their detoxification systems with their diets (Shelton 2005).

\section{Costs of induction}

The most effective form of glucosinolate defense against herbivores might be one that is present constitutively at high levels. However, plant defenses are believed to be costly so that high levels of constitutive defenses are selected for only when herbivory is high or plant parts are very valuable. When the rate of herbivory is low or unpredictable, inducible defenses may be selected to minimize costs among other benefits (Zangerl 2003). The fact that glucosinolate induction is limited to specific places and times, as discussed above, is good evidence that glucosinolates are costly. Further support for this assertion comes from studies showing that higher amounts of indolic glucosinolate induction in different genotypes of $B$. nigra were associated with later flowering times (Traw 2002). In addition, greater induction of non-indolic glucosinolates in families of wild radish (Raphanus raphanistrum) was associated with reduction in fruit mass (Agrawal et al. 2002). Moreover, the extent of glucosinolate induction is negatively correlated with the level of constitutive glucosinolates in B. nigra families (Traw 2002) and A. thaliana ecotypes (Bidart-Bouzat et al. 2005). All these lines of evidence indicate that glucosinolate induction incurs sizable costs, and so is not likely to persist evolutionarily unless it provides increased protection from herbivores accompanied by substantial fitness benefits. However, inferring costs for glucosinolate induction is problematic because glucosinolates may have other roles in plants, such as in protection against pathogens or in inhibiting the growth of competing plants. In addition, plants can tolerate herbivory to a certain degree and compensate by regrowth (Strauss and Agrawal 1999).

\section{Future perspective}

The induction of glucosinolates by herbivores shares many characteristics with the induction of other plant defense compounds. Induction is widespread and sometimes substantial, but varies with plant genotype, the organ attacked, the type of herbivore and environmental conditions. Herbivory alters the 
chemical composition of defenses as well as increasing the total amount present, and induction is often systemic as well as local. For the plant, induction is costly, but the benefits are not always clear.

There is still much to learn about the ecological significance of herbivore-induced defenses and the underlying biochemical mechanisms of induction. The glucosinolate-myrosinase system is a very appropriate subject for this research thanks to the wealth of information on its role in plant-insect interactions of the Brassicaceae. In addition, since glucosinolates are one of the many classes of secondary metabolites in A. thaliana, the unsurpassed genetic and genomic resources available for this model species can be harnessed for an assortment of biochemical, molecular and ecological studies.

Future research on glucosinolate induction would be welcome in several areas. For example, more studies on myrosinases are required to clarify how myrosinase gene transcripts, protein levels and enzyme activities change upon herbivory. In addition, more effort is needed to investigate the ecological significance of glucosinolate-myrosinase induction. The creation of $A$. thaliana transformants with different induction potential for testing with herbivores (or the judicious use of natural variation among ecotypes) could lead to significant progress in assessing the ecological value of glucosinolate and myrosinase inducibility.

The resources of $A$. thaliana should also facilitate the identification of more genes controlling induction. The results will give new insights into how plants recognize different types of herbivorous attackers and are able to elevate glucosinolate and myrosinase accumulation locally and systemically. In this work, special attention should be devoted to performing molecular, chemical and biological experiments at more time points and over longer time scales. Gene expression is usually measured over a period of hours or a few days after herbivory commences, and glucosinolate and myrosinase content measured only once or twice over a few days. However, some insects typically feed on a plant for over a week. It would be useful to know how plants respond to longer bouts of insect feeding, what the kinetics of glucosinolatemyrosinase induction over these periods is and what molecular controls regulate it.

From a plant's perspective, the costs and benefits of glucosinolate-myrosinase induction may change continuously with longer feeding bouts or other challenges, such as the presence of more than one species of herbivore or pathogen. To understand the ecological and evolutionary significance of glucosinolate-myrosinase changes at the whole plant level will require more complex experiments in which a variety of parameters are measured in addition to glucosinolate and myrosinase levels, such as growth rate, speed of development and the production of other defenses. Ultimately, glucosinolate-myrosinase induction is just one of a vast ensemble of phenotypic changes in plants following herbivory that may increase resistance to further attack and enhance the potential for regrowth. Understanding its significance is a major challenge requiring the application of molecular, biochemical and ecological methods.

Acknowledgements The authors thank their colleagues in the Department of Biochemistry for discussing many of the ideas in this review, and are grateful to the Max Planck Society for financial support.

Open Access This article is distributed under the terms of the Creative Commons Attribution Noncommercial License which permits any noncommercial use, distribution, and reproduction in any medium, provided the original author(s) and source are credited.

\section{References}

Agrawal AA (2000) Benefits and costs of induced plant defense for Lepidium virginicum (Brassicaceae). Ecology 81:1804-1813

Agrawal AA, Kurashige NS (2003) A role for isothiocyanates in plant resistance against the specialist herbivore Pieris rapae. J Chem Ecol 29:1403-1415. doi:10.1023/A: 1024265420375

Agrawal AA, Conner JK, Johnson MTJ, Wallsgrove R (2002) Ecological genetics of an induced plant defense against herbivores: additive genetic variance and costs of phenotypic plasticity. Evolution 56:2206-2213

Alvarez S, He Y, Chen S (2008) Comparative investigations of the glucosinolate-myrosinase system in Arabidopsis suspension cells and hypocotyls. Plant Cell Physiol 49:324333. doi:10.1093/pcp/pcn007

Andreasson E, Taipalensuu J, Rask L, Meijer J (1999) Agedependent wound induction of a myrosinase-associated protein from oilseed rape (Brassica napus). Plant Mol Biol 41:171-180. doi:10.1023/A:1006364607564

Barth C, Jander G (2006) Arabidopsis myrosinases TGG1 and TGG2 have redundant function in glucosinolate breakdown and insect defense. Plant J 46:549-562. doi: 10.1111/j.1365-313X.2006.02716.x

Bartlet E, Kiddle G, Williams I, Wallsgrove R (1999) Woundinduced increases in the glucosinolate content of oilseed 
rape and their effect on subsequent herbivory by a crucifer specialist. Entomol Exp Appl 91:163-167. doi:10.1023/ A:1003661626234

Bellostas N, Kachlicki P, Sorensen JC, Sorensen H (2007) Glucosinolate profiling of seeds and sprouts of B. oleracea varieties used for food. Sci Hortic 114:234-242. doi: 10.1016/j.scienta.2007.06.015

Bennett RN, Wenke T, Freudenberg B, Mellon FA, LudwigMüller J (2005) The tu 8 mutation of Arabidopsis thaliana encoding a heterochromatin protein 1 homolog causes defects in the induction of secondary metabolite biosynthesis. Plant Biol 7:348-357. doi:10.1055/s-2005-837634

Bidart-Bouzat MG, Mithen R, Berenbaum MR (2005) Elevated $\mathrm{CO}_{2}$ influences herbivory-induced defense responses of Arabidopsis thaliana. Oecologia 145:415-424. doi: 10.1007/s00442-005-0158-5

Birch ANE, Griffiths DW, Hopkins RJ, MacFarlane Smith WH, McKinlay RG (1992) Glucosinolate responses of swede, kale, forage and oilseed rape to root damage by turnip root fly (Delia floralis) larvae. J Sci Food Agric 60:1-9. doi:10.1002/jsfa.2740600102

Birch ANE, Griffiths DW, Hopkins RJ, MacFarlane Smith WH (1996) A time-course study of chemical and physiological responses in Brassicas induced by turnip root fly (Delia floralis) larval feeding. Entomol Exp Appl 80:221-223. doi:10.1007/BF00194761

Bodnaryk RP (1992) Effects of wounding on glucosinolates in the cotyledons of oilseed rape and mustard. Phytochemistry 31:2671-2677. doi:10.1016/0031-9422(92)83609-3

Bodnaryk RP (1994) Potent effect of jasmonates on indole glucosinolates in oilseed rape and mustard. Phytochemistry 35:301-305. doi:10.1016/S0031-9422(00)94752-6

Bodnaryk RP, Palaniswamy P (1990) Glucosinolate levels in cotyledons of mustard, Brassica juncea L. and rape, B. napus L. do not determine feeding rates of flea beetle, Phyllotreta cruciferae Goeze. J Chem Ecol 16:27352746. doi:10.1007/BF00988082

Bones AM, Rossiter JT (1996) The myrosinase-glucosinolate system, its organization and biochemistry. Physiol Plant 97:194-208. doi:10.1111/j.1399-3054.1996.tb00497.x

Borek V, Elberson LR, McCaffrey JP, Morra MJ (1997) Toxicity of rapeseed meal and methyl isothiocyanate to larvae of the black vine weevil (Coleoptera, Curculionidae). J Econ Entomol 90:109-112

Brader G, Tas E, Palva ET (2001) Jasmonate-dependent induction of indole glucosinolates in Arabidopsis by culture filtrates of the nonspecific pathogen Erwinia carotovora. Plant Physiol 126:849-860. doi:10.1104/pp. 126.2.849

Brown PD, Tokuhisa JG, Reichelt M, Gershenzon J (2003) Variation of glucosinolate accumulation among different organs and developmental stages of Arabidopsis thaliana. Phytochemistry 62:471-481. doi:10.1016/S0031-9422 (02)00549-6

Burmeister WP, Cottaz S, Rollin P, Vasella A, Henrissat B (2000) High resolution X-ray crystallography shows that ascorbate is a cofactor for myrosinase and substitutes for the function of the catalytic base. J Biol Chem 275:39385-39393. doi:10.1074/jbc.M006796200

Burow M, Markert J, Gershenzon J, Wittstock U (2006a) Comparative biochemical characterization of nitrile- forming proteins from plants and insects that alter myrosinase-catalysed hydrolysis of glucosinolates. FEBS J 273:2432-2446. doi:10.1111/j.1742-4658.2006.05252.x

Burow M, Müller R, Gershenzon J, Wittstock U (2006b) Altered glucosinolate hydrolysis in genetically engineered Arabidopsis thaliana and its influence on the larval development of Spodoptera littoralis. J Chem Ecol 32:2333-2349. doi:10.1007/s10886-006-9149-1

Burow M, Bergner A, Gershenzon J, Wittstock U (2007) Glucosinolate hydrolysis in Lepidium sativum-identification of the thiocyanate-forming protein. Plant Mol Biol 63:49-61. doi:10.1007/s11103-006-9071-5

Celenza JL, Quiel JA, Smolen GA, Merrikh H, Silvestro AR, Normanly J, Bender J (2005) The Arabidopsis ATR1 myb transcription factor controls indolic glucosinolate homeostasis. Plant Physiol 137:253-262. doi:10.1104/ pp.104.054395

Doughty KJ, Kiddle GA, Pye BJ, Wallsgrove RM, Pickett JA (1995) Selective induction of glucosinolates in oilseed rape leaves by methyl jasmonate. Phytochemistry 38:347350. doi:10.1016/0031-9422(94)00653-B

Eriksson S, Andreasson E, Ekbom B, Graner G, Pontoppidan B, Taipalensuu J, Zhang J, Rask L, Meijer J (2002) Complex formation of myrosinase isoenzymes in oilseed rape seeds are dependent on the presence of myrosinasebinding proteins. Plant Physiol 129:1592-1599. doi: 10.1104/pp.003285

Fahey JW, Zalcmann AT, Talalay P (2001) The chemical diversity and distribution of glucosinolates and isothiocyanates among plants. Phytochemistry 56:5-51. doi: 10.1016/S0031-9422(00)00316-2

Falk KL, Gershenzon J (2007) The desert locust, Schistocerca gregaria, detoxifies the glucosinolates of Schouwia purpurea by desulfation. J Chem Ecol 33:1542-1555. doi: 10.1007/s10886-007-9331-0

Falk KL, Tokuhisa JG, Gershenzon J (2007) The effect of sulfur nutrition on plant glucosinolate content: physiology and molecular mechanisms. Plant Biol 9:573-581. doi: 10.1055/s-2007-965431

Francis F, Lognay G, Wathelet JP, Haubruge E (2001) Effects of allelochemicals from first (Brassicaceae) and second (Myzus persicae and Brevicoryne brassicae) trophic levels on Adalia bipunctata. J Chem Ecol 27:243-256. doi: 10.1023/A: 1005672220342

Giamoustaris A, Mithen R (1995) The effect of modifying the glucosinolate content of leaves of oilseed rape (Brassica napus ssp. oleifera) on its interaction with specialist and generalist pests. Ann Appl Biol 126:347-363. doi: 10.1111/j.1744-7348.1995.tb05371.x

Gigolashvili T, Berger B, Mock HP, Müller C, Weisshaar B, Flügge UI (2007a) The transcription factor HIG1/MYB51 regulates indolic glucosinolate biosynthesis in Arabidopsis thaliana. Plant J 50:886-901. doi:10.1111/j.1365313X.2007.03099.x

Gigolashvili T, Yatusevich R, Berger B, Müller C, Flügge UI (2007b) The R2R3-MYB transcription factor HAG1/ MYB28 is a regulator of methionine-derived glucosinolate biosynthesis in Arabidopsis thaliana. Plant J 51:247261. doi:10.1111/j.1365-313X.2007.03133.x

Gigolashvili T, Engqvist M, Yatusevich R, Müller C, Flügge UI (2008) HAG2/MYB76 and HAG3/MYB29 exert a 
specific and coordinated control on the regulation of aliphatic glucosinolate biosynthesis in Arabidopsis thaliana. New Phytol 177:627-642

Gols R, Bukovinszky T, van Dam NM, Dicke M, Bullock JM, Harvey JA (2008) Performance of generalist and specialist herbivores and their endoparasitoids differs on cultivated and wild Brassica populations. J Chem Ecol 34:132-143. doi:10.1007/s10886-008-9429-z

Griffiths DW, Birch ANE, MacFarlane Smith WH (1994) Induced changes in the indole glucosinolate content of oilseed and forage rape (Brassica napus) plants in response to either turnip root fly (Delia floralis) larval feeding or artificial root damage. J Sci Food Agric 65:171-178. doi:10.1002/jsfa.2740650208

Halkier BA, Gershenzon J (2006) Biology and biochemistry of glucosinolates. Annu Rev Plant Biol 57:303-333. doi: 10.1146/annurev.arplant.57.032905.105228

Himanen SJ, Nissinen A, Auriola S, Poppy GM, Stewart CN Jr, Holopainen JK, Nerg AM (2008) Constitutive and herbivore-inducible glucosinolate concentrations in oilseed rape (Brassica napus) leaves are not affected by Bt Cryl $A c$ insertion but change under elevated atmospheric $\mathrm{CO}_{2}$ and $\mathrm{O}_{3}$. Planta 227:427-437. doi:10.1007/s00425-0070629-5

Hirai MY, Sugiyama K, Sawada Y, Tohge T, Obayashi T, Suzuki A, Araki R, Sakurai N, Suzuki H, Aoki K, Goda H, Nishizawa OI, Shibata D, Saito K (2007) Omics-based identification of Arabidopsis Myb transcription factors regulating aliphatic glucosinolate biosynthesis. Proc Natl Acad Sci USA 104:6478-6483. doi:10.1073/pnas. 0611629104

Hopkins RJ, Griffiths DW, Birch ANE, McKinlay RG (1998) Influence of increasing herbivore pressure on modification of glucosinolate content of swedes (Brassica napus spp. rapifera). J Chem Ecol 24:2003-2019. doi:10.1023/A: 1020729524818

Jost R, Altschmied L, Bloem E, Bogs J, Gershenzon J, Hahnel U, Hansch R, Hartmann T, Kopriva S, Kruse C, Mendel RR, Papenbrock J, Reichelt M, Rennenberg H, Schnug E, Schmidt A, Textor S, Tokuhisa J, Wachter A, Wirtz M, Rausch T, Hell R (2005) Expression profiling of metabolic genes in response to methyl jasmonate reveals regulation of genes of primary and secondary sulfurrelated pathways in Arabidopsis thaliana. Photosynth Res 86:491-508. doi:10.1007/s11120-005-7386-8

Kiddle GA, Doughty KJ, Wallsgrove RM (1994) Salicylic acid-induced accumulation of glucosinolates in oilseed rape (Brassica napus L.) leaves. J Exp Bot 45:1343-1346. doi:10.1093/jxb/45.9.1343

Kim JH, Jander G (2007) Myzus persicae (green peach aphid) feeding on Arabidopsis induces the formation of a deterrent indole glucosinolate. Plant J 49:1008-1019

Kim JH, Durrett TP, Last RL, Jander G (2004) Characterization of the Arabidopsis TU8 glucosinolate mutation, an allele of TERMINAL FLOWER2. Plant Mol Biol 54:671682. doi:10.1023/B:PLAN.0000040897.49151.98

Kliebenstein DJ, Figuth A, Mitchell-Olds T (2002) Genetic architecture of plastic methyl jasmonate responses in Arabidopsis thaliana. Genetics 161:1685-1696

Kliebenstein DJ, Rowe HC, Denby KJ (2005) Secondary metabolites influence Arabidopsis/Botrytis interactions: variation in host production and pathogen sensitivity. Plant J 44:25-36

Knill T, Schuster J, Reichelt M, Gershenzon J, Binder S (2008) Arabidopsis branched-chain aminotransferase 3 functions in both amino acid and glucosinolate biosynthesis. Plant Physiol 146:1028-1039. doi:10.1104/pp.107.111609

Koritsas VM, Lewis JA, Fenwick GR (1989) Accumulation of indole glucosinolates in Psylliodes chrysocephala L. -infested or -damaged tissues of oilseed rape (Brassica napus L.). Experientia 45:493-495. doi:10.1007/BF01 952043

Koritsas VM, Lewis JA, Fenwick GR (1991) Glucosinolate responses of oilseed rape, mustard and kale to mechanical wounding and infestation by cabbage stem flea beetle (Psylliodes chrysocephala). Ann Appl Biol 118:209-221. doi:10.1111/j.1744-7348.1991.tb06099.x

Kusnierczyk A, Winge P, Midelfart H, Armbruster WS, Rossiter JT, Bones AM (2007) Transcriptional responses of Arabidopsis thaliana ecotypes with different glucosinolate profiles after attack by polyphagous Myzus persicae and oligophagous Brevicoryne brassicae. J Exp Bot 58:2537-2552. doi:10.1093/jxb/erm043

Lambrix V, Reichelt M, Mitchell-Olds T, Kliebenstein DJ, Gershenzon J (2001) The Arabidopsis epithiospecifier protein promotes the hydrolysis of glucosinolates to nitriles and influences Trichoplusia ni herbivory. Plant Cell 13:2793-2807

Lazzeri L, Curto G, Leoni O, Dallavalle E (2004) Effects of glucosinolates and their enzymatic hydrolysis products via myrosinase on the root-knot nematode Meloidogyne incognita (Kofoid et White) Chitw. J Agric Food Chem 52:6703-6707. doi:10.1021/jf030776u

Levy M, Wang Q, Kaspi R, Parrella MP, Abel S (2005) Arabidopsis IQD1, a novel calmodulin-binding nuclear protein, stimulates glucosinolate accumulation and plant defense. Plant J 43:79-96. doi:10.1111/j.1365-313X. 2005.02435.x

Li Y, Kiddle G, Bennett R, Doughty K, Wallsgrove R (1999) Variation in the glucosinolate content of vegetative tissue of Chinese lines of Brassica napus L. Ann Appl Biol 134:131-136. doi:10.1111/j.1744-7348.1999.tb05245.x

Li Q, Eigenbrode SD, Stringham GR, Thiagarajah MR (2000) Feeding and growth of Plutella xylostella and Spodoptera eridania on Brassica juncea with varying glucosinolate concentrations and myrosinase activities. J Chem Ecol 26:2401-2419. doi:10.1023/A:1005535129399

Liang YS, Choi YH, Kim HK, Linthorst HJM, Verpoorte R (2006) Metabolomic analysis of methyl jasmonate treated Brassica rapa leaves by 2-dimensional NMR spectroscopy. Phytochemistry 67:2503-2511. doi:10.1016/j.phyto chem.2006.08.018

Loivamaki M, Holopainen JK, Nerg AM (2004) Chemical changes induced by methyl jasmonate in oilseed rape grown in the laboratory and in the field. J Agric Food Chem 52:7607-7613. doi:10.1021/jf049027i

Louda S, Mole S (1991) Glucosinolates: chemistry and ecology. In: Rosenthal GA, Berenbaum MR (eds) Herbivores, their interaction with secondary plant metabolites, vol 1. Academic Press, San Diego, pp 123-164

Ludwig-Müller J, Schubert B, Pieper K, Ihmig S, Hilgenberg W (1997) Glucosinolate content in susceptible and 
resistant Chinese cabbage varieties during development of clubroot disease. Phytochemistry 44:407-414. doi: 10.1016/S0031-9422(96)00498-0

Ludwig-Müller J, Bennett RN, Garcia-Garrido JM, Piche Y, Vierheilig H (2002) Reduced arbuscular mycorrhizal root colonization in Tropaeolum majus and Carica papaya after jasmonic acid application can not be attributed to increased glucosinolate levels. J Plant Physiol 159:517523. doi:10.1078/0176-1617-00731

Mari M, Leoni O, Iori R, Cembali T (2002) Antifungal vapourphase activity of allyl-isothiocyanate against Penicillium expansum on pears. Plant Pathol 51:231-236. doi: 10.1046/j.1365-3059.2002.00667.x

Martin N, Müller C (2007) Induction of plant responses by a sequestering insect: relationship of glucosinolate concentration and myrosinase activity. Basic Appl Ecol 8:13-25. doi:10.1016/j.baae.2006.02.001

Maruyama-Nakashita A, Nakamura Y, Tohge T, Saito K, Takahashi H (2006) Arabidopsis SLIM1 is a central transcriptional regulator of plant sulfur response and metabolism. Plant Cell 18:3235-3251. doi:10.1105/tpc. 106.046458

Mewis IZ, Ulrich C, Schnitzler WH (2002) The role of glucosinolates and their hydrolysis products in oviposition and host-plant finding by cabbage webworm, Hellula undalis. Entomol Exp Appl 105:129-139. doi:10.1023/A: 1022176524227

Mewis I, Appel HM, Hom A, Raina R, Schultz JC (2005) Major signaling pathways modulate Arabidopsis glucosinolate accumulation and response to both phloemfeeding and chewing insects. Plant Physiol 138:11491162. doi:10.1104/pp.104.053389

Mewis I, Tokuhisa JG, Schultz JC, Appel HM, Ulrichs C, Gershenzon J (2006) Gene expression and glucosinolate accumulation in Arabidopsis thaliana in response to generalist and specialist herbivores of different feeding guilds and the role of defense signaling pathways. Phytochemistry 67:2450-2462. doi:10.1016/j.phytochem. 2006.09.004

Mikkelsen MD, Petersen BL, Glawischnig E, Jensen AB, Andreasson E, Halkier BA (2003) Modulation of CYP79 genes and glucosinolate profiles in Arabidopsis by defense signaling pathways. Plant Physiol 131:298-308. doi: 10.1104/pp.011015

Miles CI, del Campo M, Renwick JAA (2005) Behavioral and chemosensory responses to a host recognition cue by larvae of Pieris rapae. J Comp Physiol A 191:147-155. doi:10.1007/s00359-004-0580-x

Mithöfer A, Wanner G, Boland W (2005) Effects of feeding Spodoptera littoralis on Lima bean leaves. II. Continuous mechanical wounding resembling insect feeding is sufficient to elicit herbivory-related volatile emission. Plant Physiol 137:1160-1168. doi:10.1104/pp.104.054460

Moran PJ, Cheng YF, Cassell JL, Thompson GA (2002) Gene expression profiling of Arabidopsis thaliana in compatible plant-aphid interactions. Arch Insect Biochem Physiol 51:182-203. doi:10.1002/arch.10064

Müller C, Sieling N (2006) Effects of glucosinolate and myrosinase levels in Brassica juncea on a glucosinolatesequestering herbivore-and vice versa. Chemoecology 16:191-201. doi:10.1007/s00049-006-0347-7
Müller C, Boeve JL, Brakefield P (2002) Host plant derived feeding deterrence towards ants in the turnip sawfly Athalia rosae. Entomol Exp Appl 104:153-157. doi: 10.1023/A:1021202929313

Newman RM, Hanscom Z, Kerfoot WC (1992) The watercress glucosinolate-myrosinase system: a feeding deterrent to caddisflies, snails and amphipods. Oecologia 92:1-7. doi: 10.1007/BF00317255

Noret N, Meerts P, Tolra R, Poschenrieder C, Barcelo J, Escarre J (2005) Palatability of Thlaspi caerulescens for snails: influence of zinc and glucosinolates. New Phytol 165:763-772. doi:10.1111/j.1469-8137.2004.01286.x

Petersen BL, Chen SX, Hansen CH, Olsen CE, Halkier BA (2002) Composition and content of glucosinolates in developing Arabidopsis thaliana. Planta 214:562-571. doi:10.1007/s004250100659

Piotrowski M, Schemenewitz A, Lopukhina A, Müller A, Janowitz T, Weiler EW, Oecking C (2004) Desulfoglucosinolate sulfotransferases from Arabidopsis thaliana catalyze the final step in the biosynthesis of the glucosinolate core structure. J Biol Chem 279:50717-50725. doi:10.1074/jbc.M407681200

Pontoppidan B, Hopkins R, Rask L, Meijer J (2003) Infestation by cabbage aphid (Brevicoryne brassicae) on oilseed rape (Brassica napus) causes a long lasting induction of the myrosinase system. Entomol Exp Appl 109:55-62. doi: 10.1046/j.1570-7458.2003.00088.x

Pontoppidan B, Hopkins R, Rask L, Meijer J (2005) Differential wound induction of the myrosinase system in oilseed rape (Brassica napus): contrasting insect damage with mechanical damage. Plant Sci 168:715-722. doi: 10.1016/j.plantsci.2004.10.003

Price J, Laxmi A, St. Martin SK, Jang J-C (2004) Global transcription profiling reveals multiple sugar signal transduction mechanisms in Arabidopsis. Plant Cell 16:2128-2150. doi:10.1105/tpc.104.022616

Rask L, Andreasson E, Ekbom B, Eriksson S, Pontoppidan B, Meijer J (2000) Myrosinase: gene family evolution and herbivore defense in Brassicaceae. Plant Mol Biol 42:93113. doi:10.1023/A:1006380021658

Ratzka A, Vogel H, Kliebenstein DJ, Mitchell-Olds T, Kroymann J (2002) Disarming the mustard oil bomb. Proc Natl Acad Sci USA 99:11223-11228. doi:10.1073/pnas. 172112899

Renwick JAA (2002) The chemical world of crucivores: lures, treats and traps. Entomol Exp Appl 104:35-42. doi: 10.1023/A:1021231732022

Reymond P, Bodenhausen N, Van Poecke RMP, Krishnamurthy V, Dicke M, Farmer EE (2004) A conserved transcript pattern in response to a specialist and a generalist herbivore. Plant Cell 16:3132-3147. doi:10.1105/tpc.104.026120

Rojas JC (1999) Electrophysiological and behavioral responses of the cabbage moth to plant volatiles. J Chem Ecol 25:1867-1883. doi:10.1023/A:1020985917202

Rosa EAS, Heaney RK, Rego FC, Fenwick GR (1994) The variation of glucosinolate concentration during a single day in young plants of Brassica oleracea var acephala and capitata. J Sci Food Agric 66:457-463. doi: 10.1002/jsfa.2740660406

Rostàs M, Bennett R, Hilker M (2002) Comparative physiological responses in Chinese cabbage induced by 
herbivory and fungal infection. J Chem Ecol 28:24492463. doi:10.1023/A:1021427917603

Sarosh BR, Meijer J (2007) Transcriptional profiling by cDNAAFLP reveals novel insights during methyl jasmonate, wounding and insect attack in Brassica napus. Plant Mol Biol 64:425-438. doi:10.1007/s11103-007-9164-9

Sasaki-Sekimoto Y, Taki N, Obayashi T, Aono M, Matsumoto F, Sakurai N, Suzuki H, Hirai MY, Noji M, Saito K, Masuda T, Takamiya K, Shibata D, Ohta H (2005) Coordinated activation of metabolic pathways for antioxidants and defence compounds by jasmonates and their roles in stress tolerance in Arabidopsis. Plant J 44:653668. doi:10.1111/j.1365-313X.2005.02560.X

Schuster J, Knill T, Reichelt M, Gershenzon J, Binder S (2006) BRANCHED-CHAIN AMINOTRANSFERASE4 is part of the chain elongation pathway in the biosynthesis of methionine-derived glucosinolates in Arabidopsis. Plant Cell 18:2664-2679. doi:10.1105/tpc.105.039339

Shelton AL (2005) Within-plant variation in glucosinolate concentrations of Raphanus sativus across multiple scales. J Chem Ecol 31:1711-1732. doi:10.1007/s10886-005$5922-9$

Siemens DH, Mitchell-Olds T (1996) Glucosinolates and herbivory by specialists (Coleoptera, Chrysomelidae, Lepidoptera, Plutellidae) — consequences of concentration and induced resistance. Environ Entomol 25:1344-1353

Siemens DH, Mitchell-Olds T (1998) Evolution of pestinduced defenses in Brassica plants: tests of theory. Ecology 79(2):632-646

Skirycz A, Reichelt M, Burow M, Birkemeyer C, Rolcik J, Kopka J, Zanor MI, Gershenzon J, Strnad M, Szopa J, Mueller-Roeber B, Witt I (2006) DOF transcription factor AtDof11 (OBP2) is part of a regulatory network controlling glucosinolate biosynthesis in Arabidopsis. Plant $\mathrm{J}$ 47:10-24. doi:10.1111/j.1365-313X.2006.02767.x

Smallegange RC, van Loon JJA, Blatt SE, Harvey JA, Agerbirk N, Dicke M (2007) Flower vs leaf feeding by Pieris brassicae: glucosinolate-rich flower tissues are preferred and sustain higher growth rate. J Chem Ecol 33:18311844. doi:10.1007/s10886-007-9350-x

Smith BJ, Kirkegaard JA (2002) In vitro inhibition of soil microorganisms by 2-phenylethyl isothiocyanate. Plant Pathol 51:585-593. doi:10.1046/j.1365-3059.2002. 00744.x

Soler R, Bezemer TM, Van der Putten WH, Vet LEM, Harvey JA (2005) Root herbivore effects on above-ground herbivore, parasitoid and hyperparasitoid performance via changes in plant quality. J Anim Ecol 74:1121-1130. doi: 10.1111/j.1365-2656.2005.01006.x

Sonderby IE, Hansen BG, Bjarnholt N, Ticconi C, Halkier BA, Kliebenstein DJ (2007) A system biology approach identifies a R2R3 MYB gene subfamily with distinct and overlapping functions in regulation of aliphatic glucosinolates. PLoS One 2:e1322.doi:10.1371/journal.pone. 0001322

Strauss SY, Agrawal AA (1999) The ecology and evolution of plant tolerance to herbivory. Trends Ecol Evol 14:179185. doi:10.1016/S0169-5347(98)01576-6

Taipalensuu J, Falk A, Rask L (1996) A wound- and methyl jasmonate-inducible transcript coding for a myrosinase- associated protein with similarities to an early nodulin. Plant Physiol 110:483-491. doi:10.1104/pp.110.2.483

Taipalensuu J, Andreasson E, Eriksson S, Rask L (1997) Regulation of the wound-induced myrosinase-associated protein transcript in Brassica napus plants. Eur J Biochem 247:963-971. doi:10.1111/j.1432-1033.1997.00963.x

Travers-Martin N, Müller C (2007) Specificity of induction responses in Sinapis alba L. and their effects on a specialist herbivore. J Chem Ecol 33:1582-1597. doi: 10.1007/s10886-007-9322-1

Traw MB (2002) Is induction response negatively correlated with constitutive resistance in black mustard? Evolution 56:2196-2205

van Dam NM, Raaijmakers CE (2006) Local and systemic induced responses to cabbage root fly larvae (Delia radicum) in Brassica nigra and B. oleracea. Chemoecology 16:17-24. doi:10.1007/s00049-005-0323-7

van Dam NM, Witjes L, Svatos A (2003) Interactions between aboveground and belowground induction of glucosinolates in two wild Brassica species. New Phytol 161:801810. doi:10.1111/j.1469-8137.2004.00984.x

Vergara F, Svatos A, Schneider B, Reichelt M, Gershenzon J, Wittstock U (2006) Glycine conjugates in a lepidopteran insect herbivore - the metabolism of benzylglucosinolate in the cabbage white butterfly, Pieris rapae. ChemBioChem 7:1982-1989. doi:10.1002/cbic.200600280

Vierheilig H, Bennett R, Kiddle G, Kaldorf M, Ludwig-Müller J (2000) Differences in glucosinolate patterns and arbuscular mycorrhizal status of glucosinolate-containing plant species. New Phytol 146:343-352. doi:10.1046/j.14698137.2000.00642.x

Vlieger L, Brakefield PM, Müller C (2004) Effectiveness of the defense mechanism of the turnip sawfly, Athalia rosae (Hymenoptera: Tenthredinidae) against predation by lizards. Bull Entomol Res 94:283-289. doi:10.1079/BER 2004299

Wittstock U, Kliebenstein DJ, Lambrix V, Reichelt M, Gershenzon J (2003) Glucosinolate hydrolysis and its impact on generalist and specialist insect herbivores. In: Romeo JT (ed) Integrative phytochemistry: from ethnobotany to molecular ecology. Recent advances in phytochemistry, vol 37. Pergamon, pp 101-124

Wittstock U, Agerbirk N, Stauber EJ, Olsen CE, Hippler M, Mitchell-Olds T, Gershenzon J, Vogel H (2004) Successful herbivore attack due to metabolic diversion of a plant chemical defense. Proc Natl Acad Sci USA 101:4859-4864

Wurst S, Langel R, Rodger S, Scheu S (2006) Effects of belowground biota on primary and secondary metabolites in Brassica oleracea. Chemoecology 16:69-73. doi: 10.1007/s00049-005-0328-2

Zangerl AR (2003) Evolution of induced plant responses to herbivores. Basic Appl Ecol 4:91-103. doi:10.1078/ 1439-1791-00135

Zhang Z, Ober JA, Kliebenstein DJ (2006) The gene controlling the quantitative trait locus EPITHIOSPECIFIER MODIFIER1 alters glucosinolate hydrolysis and insect resistance in Arabidopsis. Plant Cell 18:1524-1536. doi: 10.1105/tpc. 105.039602 